\title{
COMPUTATIONAL ARRANGEMENT OF DEMOLITION DEBRIS
}

\author{
Daniel Marshall *, Caitlin Meuller, Brandon Clifford and Sheila Kennedy \\ Department of Architecture, Massachusetts Institute of Technology, 77 Mass Ave, MA 02139 Cambridge, United States
}

Article Info:
Received:
27 January 2020
Revised:
23 March 2020
Accepted:
6 April 2020
Available online:
23 July 2020
Keywords:
Concrete
Rubble
Demolition
Recycling
Holding patterns
Construction waste
Sustainability

\begin{abstract}
The average builder in the USA provides a warrantee for 10 years, and the US Department for Energy calculates that US office buildings have an average lifespan of 73 years. No building is permanent, and all will face demolition at some point. When a building comes to the end of its safe and useful lifespan, there is no method for re-using the material in new buildings, instead, all constructions today require virgin material. This is a problem for sustainability because US cities, like most other global cities, require cyclical replacement of ageing buildings, and therefore perpetual resource extraction. This paper provides techniques for computationally arranging materials after the demolition and unmaking of architecture. Rather than downcycling concrete into low-value aggregate or melting float glass into opaque bottles methods are shown for this material to be indexed, re-machined and algorithmically arranged into new assemblies. These assemblies are conceived of as holding patterns; an indexed library of materials that are put into useful architectural arrangements, but ready to be disassembled towards some future use. These holding patterns are used as infill to the city rather than landfill beyond. Rather than building for sixty-year life spans, the project offers an imagination of eternal re-constructions that can learn from the carcass of past buildings. Based on rough estimates 2016 could be the first year where there exists more than one trillion tons of concrete on earth. More than the total weight of living trees on the planet (Crowther et al. 2015; USGS, 2018). This paper begins to develop new aptitudes for re-fitting misfit material rather than consuming evermore.
\end{abstract}

\section{INTRODUCTION}

Each year, roughly 16 million tons of demolition waste is discarded from the New York City Tristate region (EPA, 2018). The origin of this material is predominantly buildings, however, the replacement of roads and bridges, and urban landscape can contribute to the total weight of material that is thrown away (Figure 1). In New York the development pressures drive the continual replacement of buildings, for instance the Empire State Building exists on a plot of land that had seen a collection of brick houses, followed by 36 years of the Waldorf-Astoria Hotel before the Empire State Building was erected in 1930 (Moe, 2017). Despite the sublime character of New York's architecture, the buildings are far from eternal. For instance, the 22 story tall Hanover National Bank Building was demolished in 1931 after just 28 years. Today in 2018 there are debates on JP Morgan's plans to demolish the Union Carbide building, which would be the first building over 200 $\mathrm{m}$ to be demolished, standing at 52 stories after 68 years (Shaw, 2018).

Whatever the cause of a buildings replacement, this paper points out that the urban fabric has not been built to last permanently. Even the everlasting iconic Eiffel Tower has seen each piece of its steel structure replaced at least twice during its 130-year life span (Moe, 2017). Buildings and urban infrastructure will inevitably reach the end of a safe life-cycle, and require replacement.

But one can just recycle this material, correct? The first step to reusing this material is to understand the shape of the demolition debris - what happens to the fabric of architecture when it is unmade.

The majority of demolition material is concrete, with 8.2 million tons being produced each year. Two-thirds of this material is typically taken to landfill outside New York State. The other third is "recycled". In reality the material is ground up into a fine powder to be mixed with new cement, sand and water to make new concrete. Of course, this recycling process only eliminates some aggregates, and not cement, which is the most unsustainable part of concrete manufacturing, requiring coke to be burnt 2700 degrees Fahrenheit. This concrete is not a high enough grade for building; rather it is only suitable for road surfaces. In other words, when you demolish a concrete building there exists no way of using that material to "recycle" it 


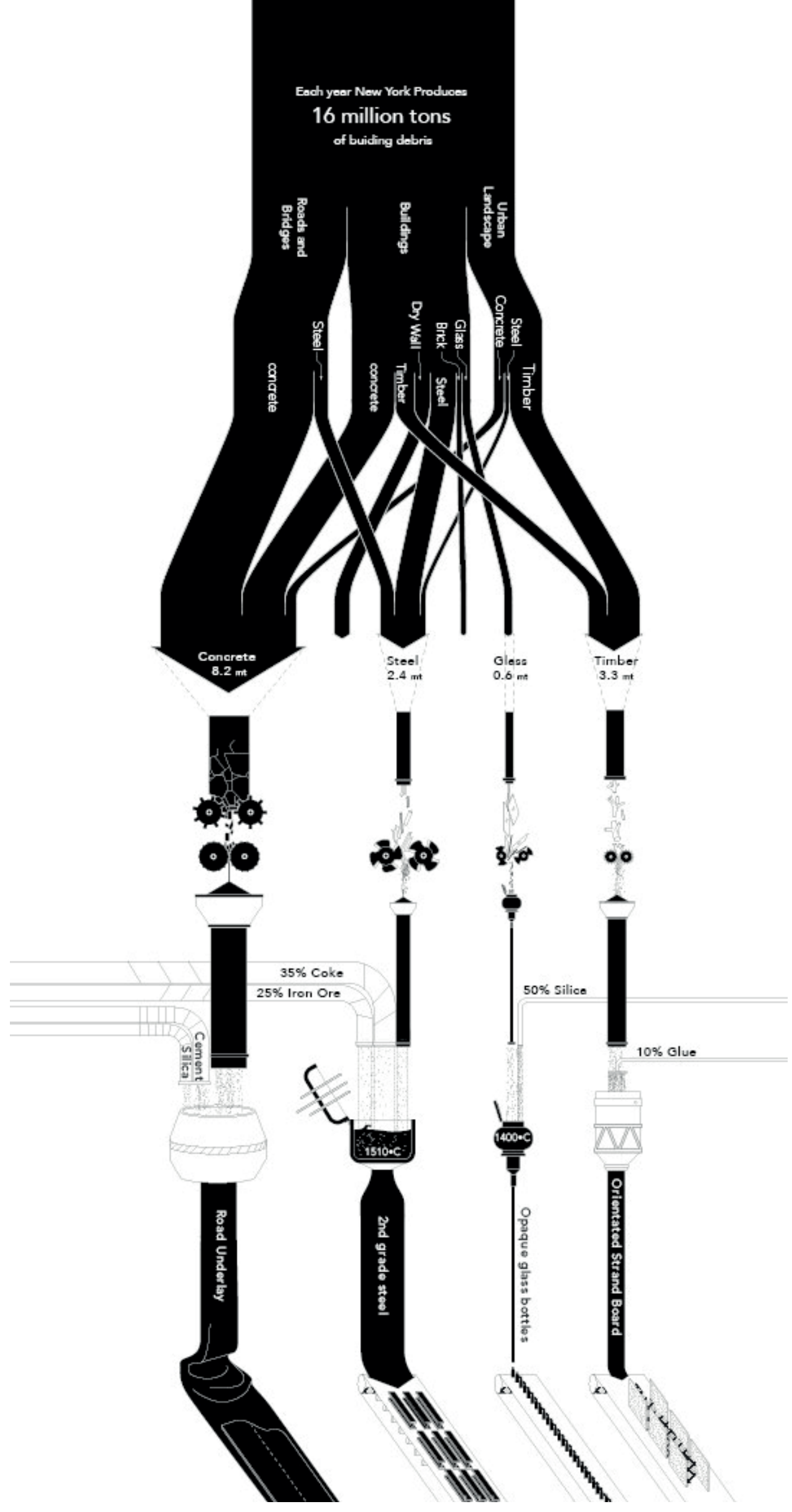

FIGURE 1: Best practice concrete recycling process illustrated based on research by Irmak Turan (2016) "From sink to stock: the potential for recycling materials from the existing built environment". 
into a new building. Instead the concrete is downcycled and the replacement building must be constructed with new material.

Demolition of glass from the built environment follows a similar trajectory. The glass is shredded and then remelted with additional silica. However this new material is only useful for making bottles as it is not clear enough for the crystal glass that New Yorkers are accustomed to. When steel is recycled it is typically mixed $50 \%$ fresh coke and $25 \%$ virgin iron ore because the $100 \%$ recycled steel has structural impurities that make it useless for building construction.

The culture of construction that exists within New York City today may claim to be sustainable and recyclable, but this is a fallacy. Instead, the demolition of buildings leads to a down-cycling of material, and fresh extraction of new material to replace that which was removed (Figure 2).

There have been many calls for municipal recycling schemes that encourage the population to preserve precious material. For instance, Rania Ghosn and Jazairy el Hadi study the "Geographies of Trash" ${ }^{\text {w }}$ with their focus on municipal waste. Yet the volumes of trash produced by the construction industry far outweigh the industrial and municipal waste streams. Are there alternative ways that architects might do more to address their unsustainable industry? Can architects begin to make use of the epic amounts of byproduct material that are already being produced in the city as it exists today?

\section{MAPPING NEW YORK'S CEMETERY OF DEMOLISHED BUILDINGS}

According to the New York City (NYC) building permit data, there have been 14,885 demolitions in the city since 1989. This information can be mapped out through the city to give a sense of the hot-spots of these most recent demolitions (Figure 3). Many demolitions are focused in areas of redevelopment, yet also around Carney Island and Jamaica Bay, following Superstorm Sandy.

Figure 4 shows the locations of trash moving out of New York. Construction debris is taken to transit facilities by building contractors or demolition teams. This material is sorted at the transit facility before being taken to landfill locations across the east coast.

New York regulations state that companies cannot take demolition material to landfill. The reason for these stringent regulations is political. Historic landfills have taken garbage, septage, medical waste, and industrial waste into C\&D landfills, and thus created numerous environmental problems to communities and landscapes living around landfill sites. The state imposes high fines for any landfill that accepts construction debris, $\$ 2,500$ for each violation, with an additional penalty of up to $\$ 1,000$ for each day during which such violations continue.

The result of these regulations is a large network of landfill sites in nearby states which accept construction demolition debris. Often as much as $\mathbf{5 0 0}$ miles away. The majority of this material is taken by truck transportation.

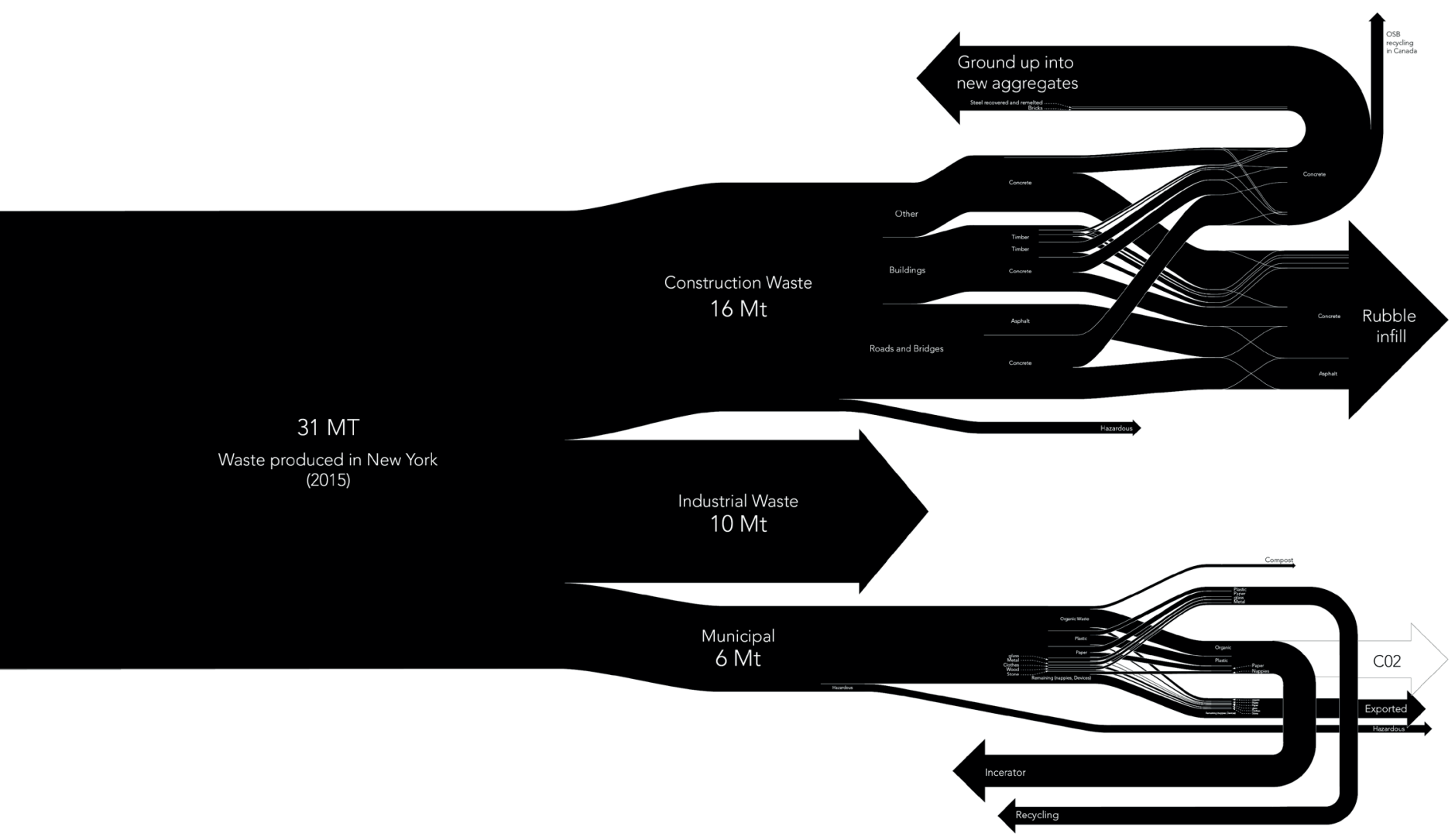

FIGURE 2: Diagram based on Data from a survey of construction and demolition waste by the EPA. Environmental Protection Agency, Office of Resource Conservation and Recovery (2018) "Construction and Demolition Debris Generation in the United States". 


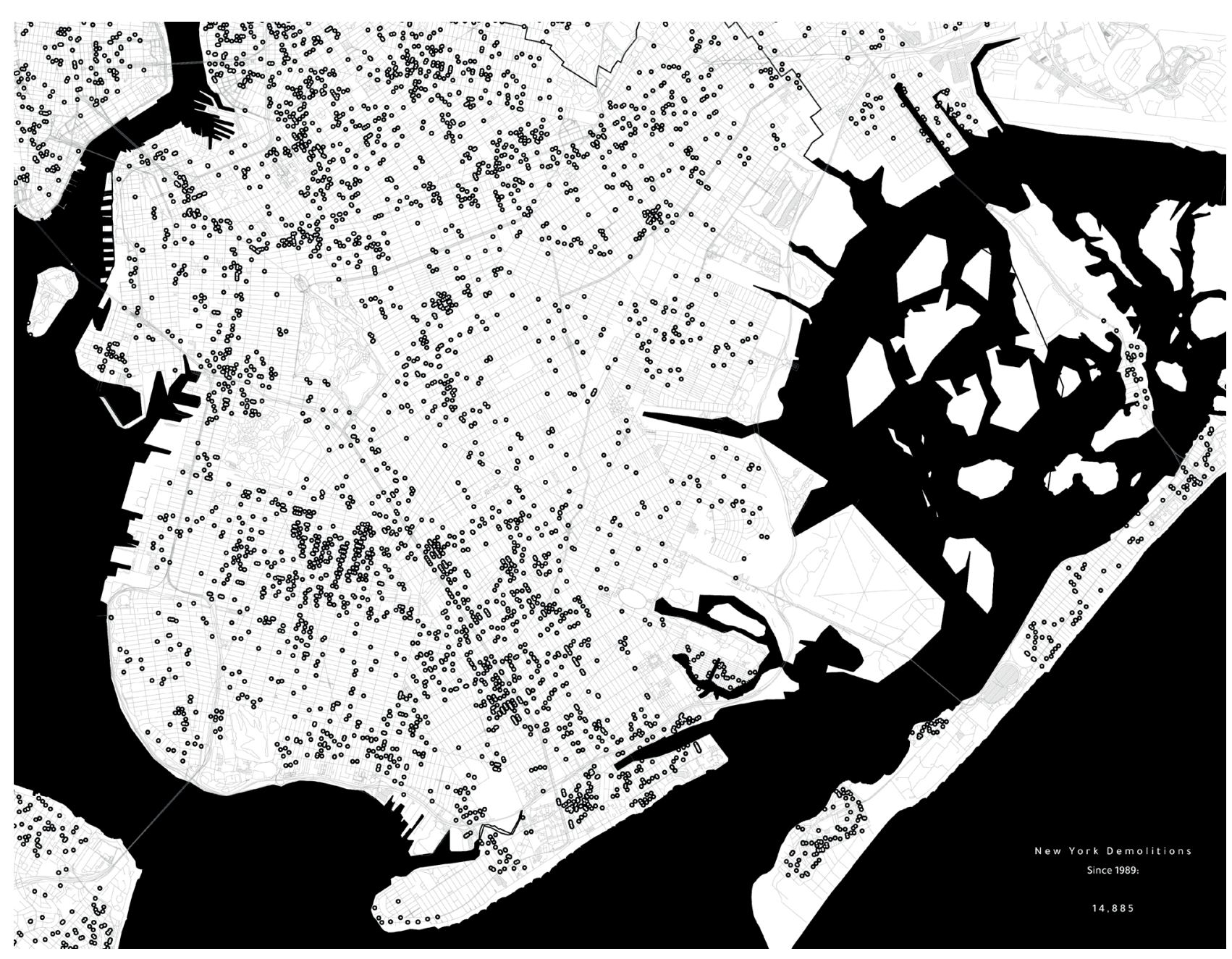

FIGURE 3: Based on New York City building permit data since 1989 there have been 14,885 demolitions.

Each mile of a typical truck taking 15 tons of material costs \$1.09: \$0.375 for the driver's salary, \$0.17 for fuel, \$0.545 for other insurance, truck costs, taxes etc. Demolition and construction waste creates a large market for this transportation, with 22,000 tons of material taken to landfill per day from New York.

The cost of disposing of construction debris is therefore a balance between state-level regulations and the distance involved. Demolition companies like Waste Management maintain ownership over dozens of landfill sites across the east coast such that they can respond to changes in landfill from different locations. The net result of the economic cost of taking a tonne of material to a NYC trash transit facility to be taken out of state is $\$ 75$. With this $\$ 75$ charge the cost of just dealing with the demolished material from a typical house, weighing 80 tons, would be $\$ 6,000$. This is a significant factor in recycling, as heavier materials will be more beneficial to keep in the context that they were produced.

\subsection{Economic and technical development of the de- molition waste industry}

Until 1925 demolition teams were willing to pay for a building to demolish because of the value that could be yielded through salvage; however, by 1929 both the value of labour per hour increased, and the cost of building material reduced making it more profitable dump scrap material. The last scavengers in New York were roving wood merchants, filling up a cart for $\$ 10$ and selling it as firewood to tenements in the early 1930s. The movement away from masonry towards steel and glass meant that many of the buildings being removed were no longer useful to the construction industry. Just as modernity encouraged a fleeting aesthetic that was dislocated from historic materials, recycling brick masonry became a practice lost to the annals of history.

Since the patent of the Bulldozer in 1932, buildings have been transformed from building to debris without regard for the potential value of the material. There was public outcry in 1955 when demolition companies smashed up granite bathrooms in the Hotel Majestic West 72nd Street; the contractor argued: "To recut the rosewood, mahogany and black walnut used in the interiors of the old glow room and the rose room... would have cost more than to use new materials".

Blowing up a building creates dust that is illegal in accord with clean air regulations, and so it's use in cities is limited to isolated council estates or stadiums in the middle of large parking lots. 
Recent inventions of the hydraulic excavator jaw and concrete slab saw are designed to help expedite the process of removing material in economies where construction labour is expensive. Unlike the wrecking ball, the jaw and slab saw are also particularly specialized for cutting large amounts of steel reinforcement that exist within the concrete, with replaceable blades that can be kept sharp. These are the tools that define the state of the art in contemporary demolition, and as such the paper takes the output of these machines as the ingredients for the holding patterns.

Today, the waste management and recycling industry is a multi-million dollar practice. Most revenue comes from lorries that are weighed before and after dumping their load at transit stations scattered throughout New York City. They typically pay $\$ 75$ per tonne.

The economics favour large conglomerates that can merge landfills with trash collection and large-scale distribution networks of trains and trucks that can help minimize the costs. States that are keen to bring in business might sacrifice environmental standards to encourage high-value contracts with large multistage conglomerate businesses.

\subsection{New York's rubble concrete mountain}

Visualising the volume of scrap materials can help to contemplate what design responses might be necessary. Each year New York Tri-State Region disposes of 8.2 million tonnes of concrete. Using the basic density of concrete ate $2,400 \mathrm{~kg} / \mathrm{m}^{3}$, this would equate to about 3.4 million cubic meters per year. If one were to pile this concrete up into one huge concrete mountain, it would begin to settle at an angle of repose, at about 20 degrees. Using this information one can begin to imagine the volume of the concrete mountain that New York tristate C\&D waste would amount to (Figures 5-6).

\subsection{New York's scrap glass ceiling}

Similarly, it is helpful to visualise the amount of glass that gets discarded each year such that one could begin to speculate on what architectural possibilities might exist for this volume of material. In the case of glass, over six hundred thousand tons of material are disposed of within the Tristate region each year. Of course, all of this glass is differ-

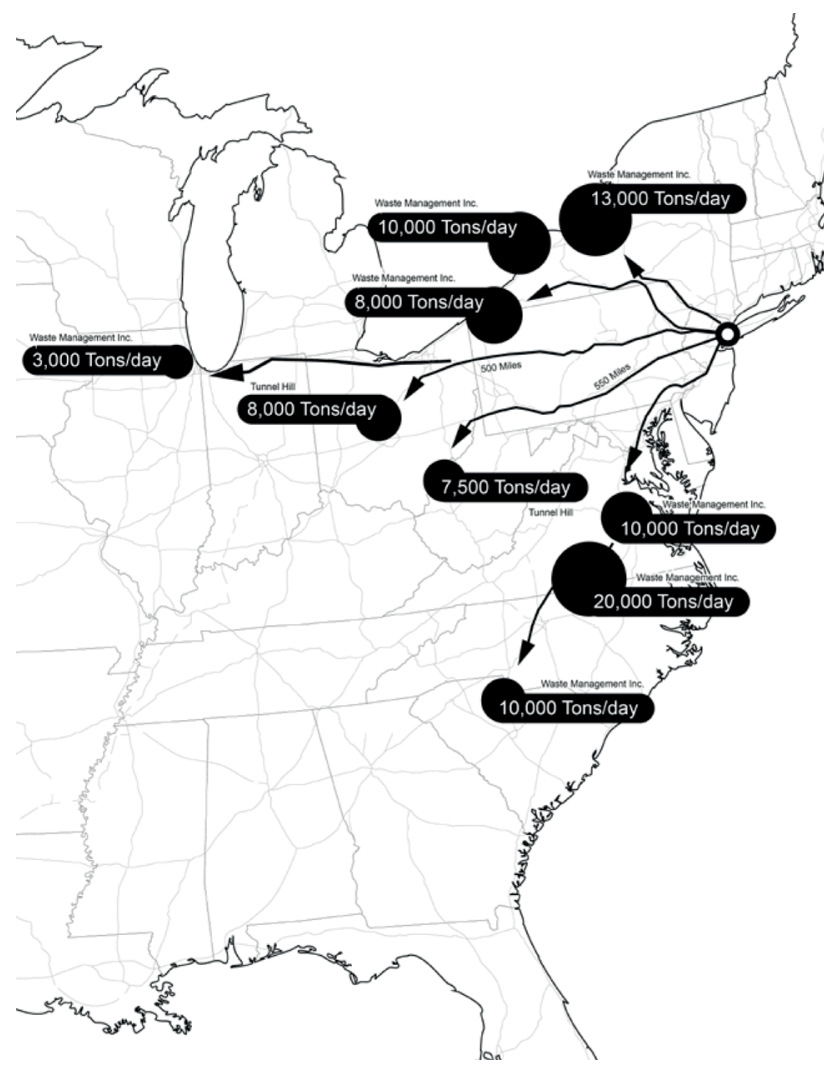

FIGURE 4: Out of state landfills for accepting construction and demolition debris from New York. The map also shows the volume of material they are permitted to accept according to the company website.

ent size and different grades. But if one where to find a way to arrange them all together in one surface, the glass trash since 1955 would measure 6,320m square (Figures 7-8).

\subsection{The future of demolition material in New York City}

Whether one is shocked or awed by the volume of scrap concrete, glass and steel produced historically in New York, these quantities pale in comparison to quantities of scrap material that are due to be generated in the future. Each

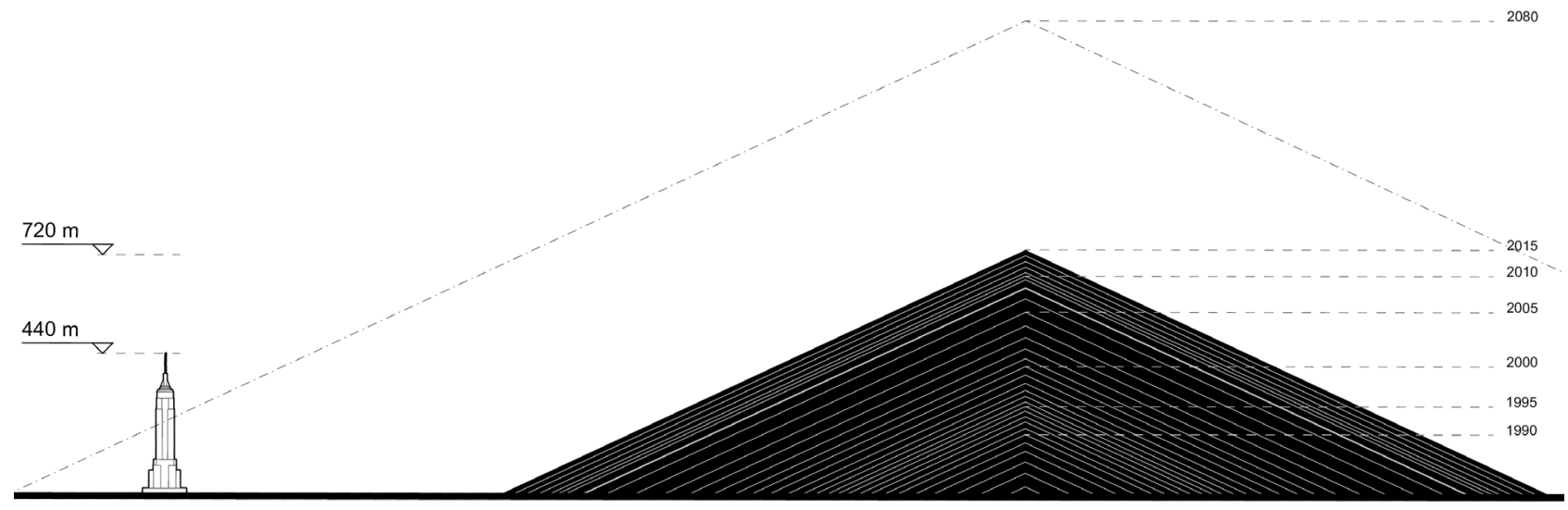

FIGURE 5: Diagram based on data from a survey of construction and demolition waste by the EPA - Environmental Protection Agency, Office of resource conservation and recovery (2018), "Construction and demolition debris generation in the United States". 


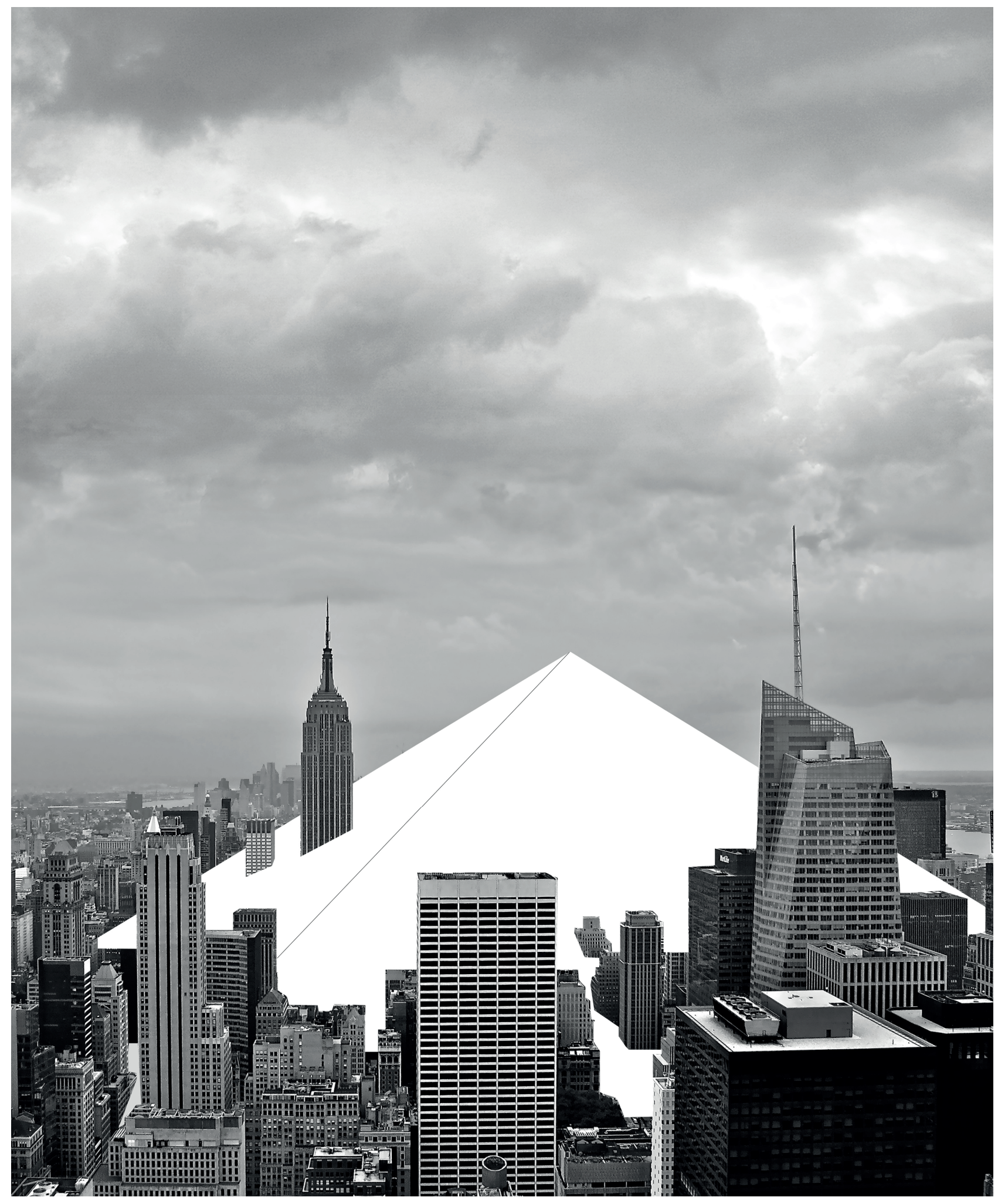

FIGURE 6: Visualisation to indicate the mountainous volumes of concrete that have been demolished within the New York Tristate Region since 1989.

year, the United States Geological Survey publishes data on the global production of cement. If one adds up the cement produced each year in a cumulative graph this dataset can show the total volume of cement produced in human history - roughly 200 million tons. Of course, cement is just one-fifth of the concrete mixture, so the total volume of concrete would be equivalent to one trillion tons in human history.

The European Union suggest that $20 \%$ of all concrete structures ever made have already been demolished (Huu- 


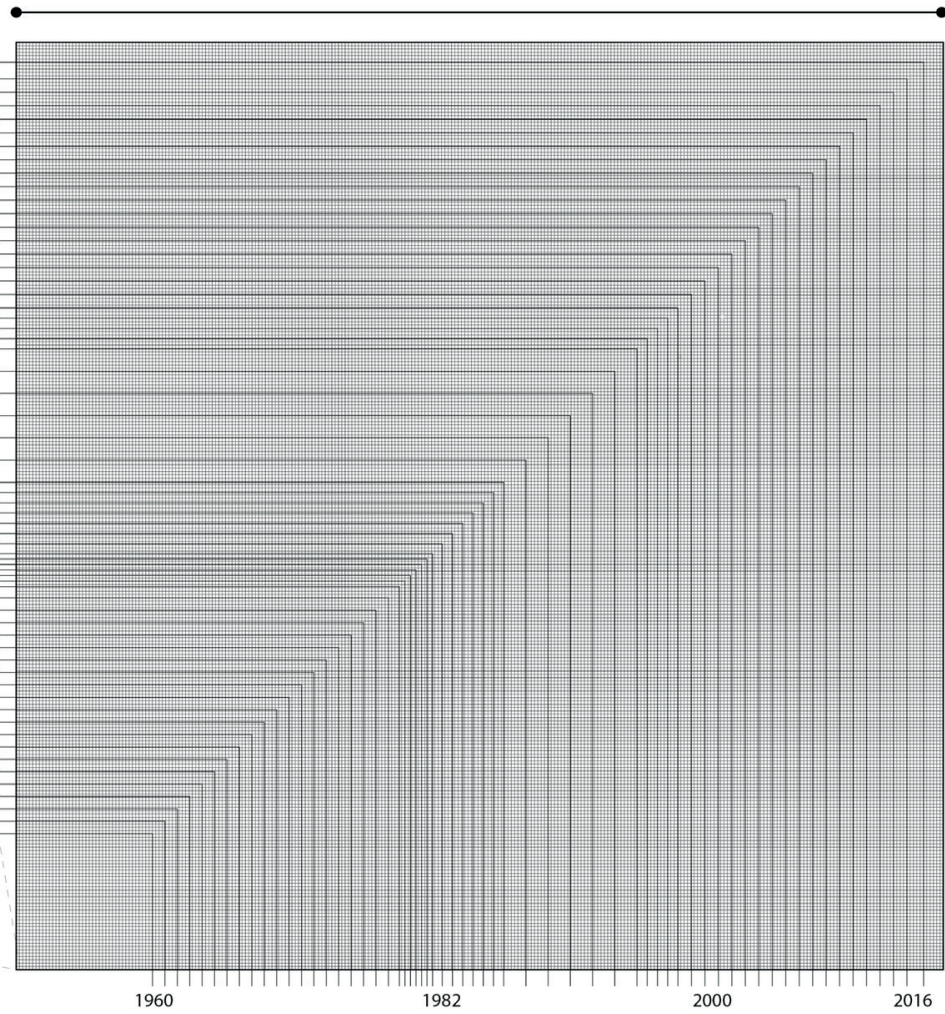

FIGURE 7: If New York arranged all of the glass demolished since 1955, the city could make a glass ceiling approximately $6320 \mathrm{~m}$ square.

hka \& Lahdensivu, 2016). When the proportion of demolished buildings is overlaid with the accumulation of concrete globally, one can begin to see that there is a lag time between the casting of concrete buildings and the demolition of the building. Concrete structures have a lifespan of around 60 years, and the peak of concrete production has been between 1960-2015. As such, there is likely to be a large and steady increase in the amount of concrete rubble produced globally over the next decades (Figure 9).

\section{A BRIEF HISTORY OF COMPUTATIONAL METHODS FOR SOLVING IRREGULAR JIGSAW PUZZLES}

In response to the abundance of demolition material presented in the preceding sections, this paper proposes computational methods for recycling irregular demolition material into new salvaged constructions. If demolition debris can be input into three-dimensional design software (through scanning) the resulting library of trash can be used as a catalogue for designing new constructions. This is not the first piece of research to propose the use of computer algorithms for solving irregular jigsaw puzzles and it is necessary to situate this research within a broader historical context.

The megalithic sternotomy of Inca masons is remarkable for the range of idiosyncratic approaches to arranging irregular material that, while not computational, demonstrate precise algorithmic thinking. As documented by Brandon Clifford in the Cannibal's cookbook, this culture of stone cutting and arranging "rubble" stones can also be found across the planet, for instance, the Edo castle in Tokyo, or the Osirieon Temple in Egypt (Clifford, 2017).

Computational methods for finding ways to fit shapes in space might trace back to the hunt for the "perfect squared square" at Trinity College, Cambridge during the run-up to the Second World War. The squared square is a square that is made up of other squares, and the subsquare of the "perfect squared square" are each different. The students that worked on this problem transformed the square tiling into an equivalent electrical circuit - they called it "Smith diagram" - by considering the squares as resistors that connected to their neighbours at their top and bottom edges and then applied Kirchhoff's circuit laws and circuit decomposition techniques to that circuit. This was the beginning of graph theory, and the students went on to apply the thinking at Bletchley Park during the war (Brooks et al., 1940).

According to graph theory, a "graph" is a structure comprised of a set of related objects, such as related pairs of vertices forming edges, which can be arcs or lines (Cormen et al., 2001). This paper uses the Hungarian method - an algorithm that finds maximum-weight matchings in bipartite graphs, or in more simple terms, a set of vertices that can be partitioned into two distinct sets where no vertices share a common edge (Ahuja et al., 1993). The Hungarian method was published in 1955 by mathematicians Denes Konig and Jeno Egervary. It is also called the assignment problem, which is commonly used in operations optimization, transportation and even naval research. This paper ap- 


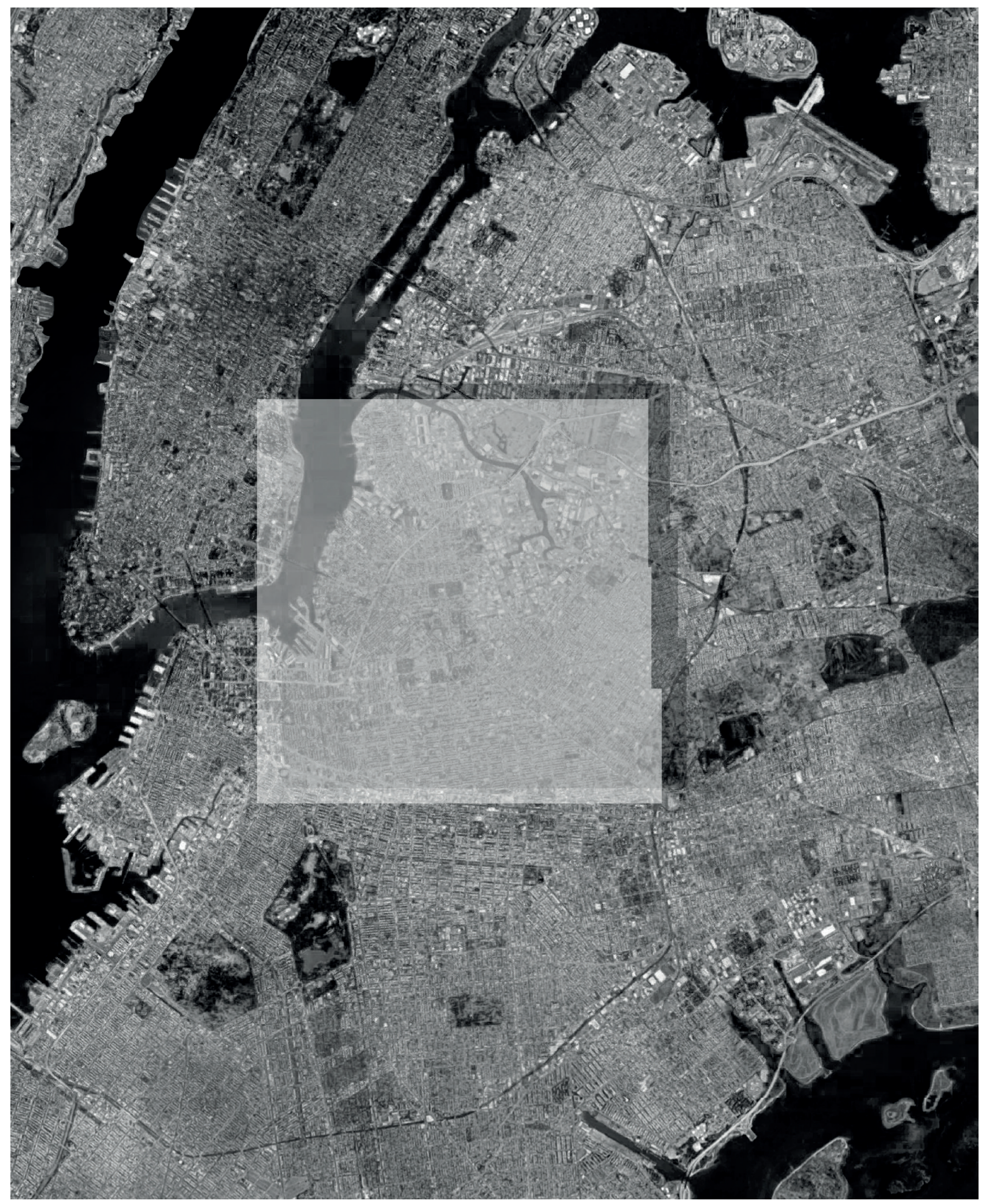

FIGURE 8: Visualisation to indicate the $6320 \mathrm{~m}$ scarp glass ceiling for scale.

plies the logic of bipartite graphs to match distinct sets of irregular materials in architectural assemblies.

Computational Evolutionary algorithms for the arrangement of objects may have been first credited to Adrian Thompson at the University of Sussex, who created an algorithm that could incrementally adjust the layout of elements on a silicon chip. These evolutionary optimization algorithms are utilized in the paper in conjunction with the Hungarian algorithm. The Hungarian algorithm provides a score of best match, of the library of material into the tar- 
get structure. The evolutionary algorithms then adjust the configuration of the target geometry to optimize the match.

Within contemporary digital design discourse, the idea of scanning objects, and then arranging them in computational space might originate with Greg Lynn's recycled toy furniture, where rubber ducks were scanned and Boolean-union joined together into aggregate tables that were then fabricated (Lynn, 2008). Jonathan Enns' thesis "The New Non-Standard" investigated the scanning timber elements for use in irregular constructions. Later researchers at Hooke Park combined this research from Enns with genetic optimization algorithms to re-adjust the arrangement of branches into the best fit (Enns, 2010; Mollica \& Self, 2016). Most recently, the Harvard GSD Assistant Professor Andrew Witt and his firm, Certain Measures, have shown algorithms that utilize publicly available artificial intelligence algorithms, to organize scrap material and re-arrange it into facade systems (Witt et al, 2017). The research of Certain Measures, organizes scrap into search engines using artificial intelligence libraries, and then selects the best fit at each step along the process, adapting the target shape in to accommodate the library of material as best as possible.

The use of Neural Networks and Machine Learning to sort through trash is also being implemented by Zen Robotics, a company in Germany that uses image recognition algorithms to sort trash into different recycle streams. The future work suggested by this paper would involve the use of machine learning to address two key challenges. Firstly in providing a low-cost method for identifying and grading the structural quality of waste material. Secondly as further research for the creation of algorithms that can solve the zig-saw puzzle problem posed by irregular material to meet the challenges posed by the character of the concrete, glass and timber that emerges through the demolition stream, and in ever more precise ways.

\section{COMPUTATIONAL ARRANGEMENT OF CONCRETE DEBRIS}

Based on the principals of structural bending, $70 \%$ of the structure exists in the floor-plate. Within a concrete building this means that most material not in the walls, but rather in the flat cast slab with steel reinforcement mesh. Floor plates are most commonly cut apart using a slab saw; 100 hp diesel engines spinning diamond-tipped saws with pressured water to help remove dust. Extracting concrete from both floor-plates and Plattenblau buildings would therefore yield a collection of irregular concrete that is roughly rectangular, but perhaps with some chipped corners (Figure 10).

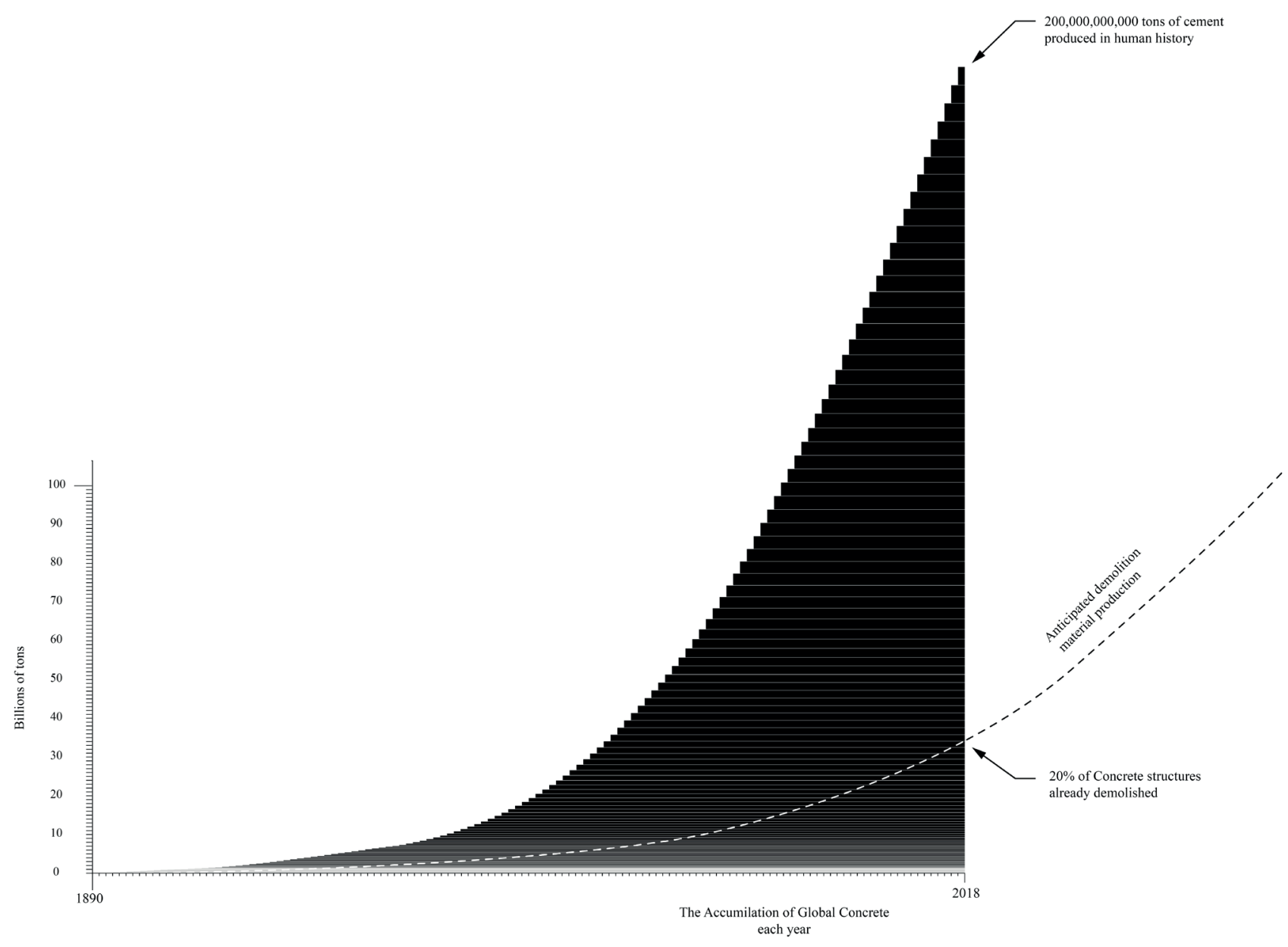

FIGURE 9: The accumulation of global concrete each year, based on data from the USGS (2018) "Minerals commodity summaries: cement statistical compendium". 


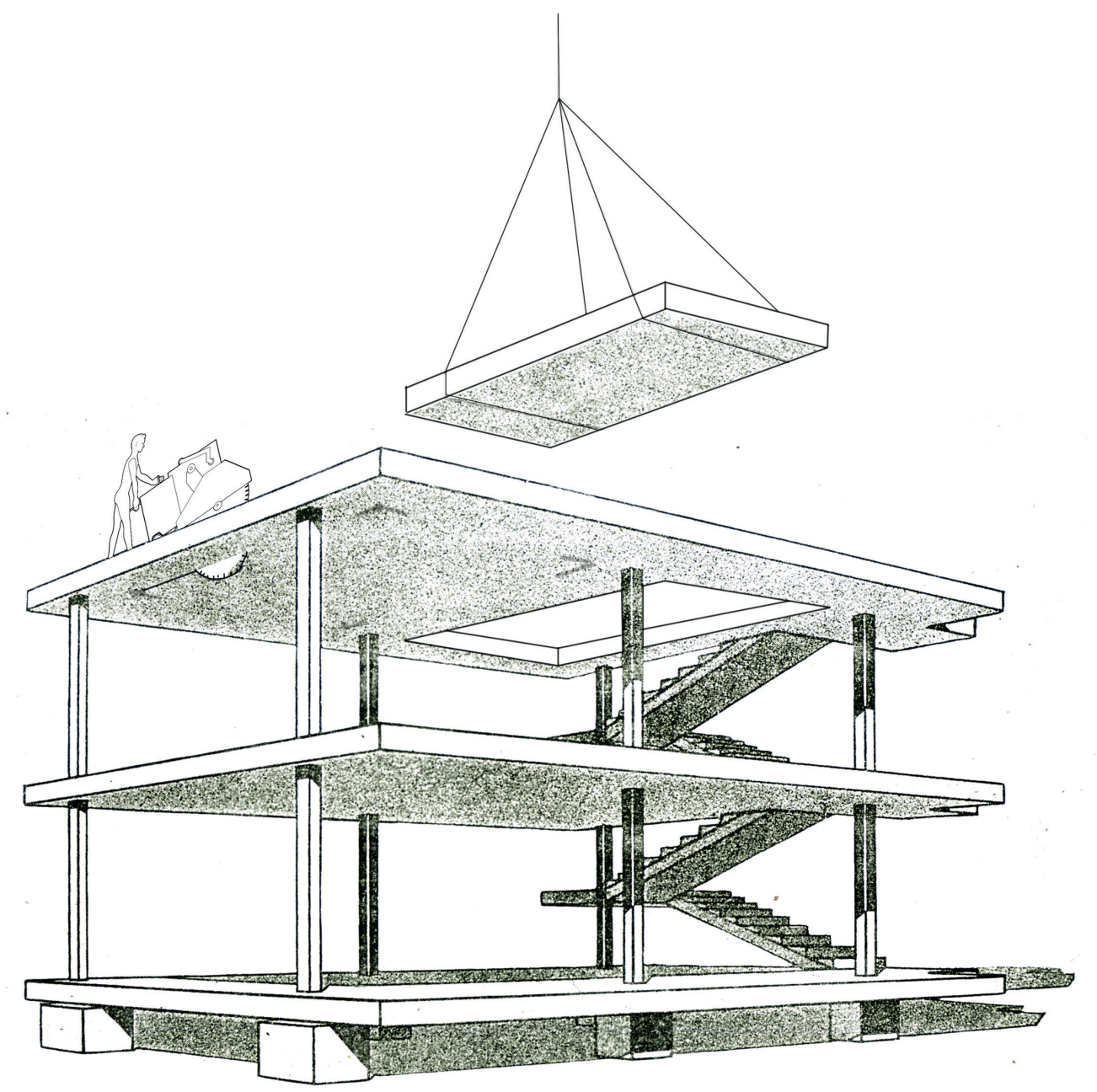

FIGURE 10: Le Corbusier created the Domino House in 1915. The Design for the house reveals the distribution of concrete within the design. Most of the material being positioned within the floorplate The diagram speculates on the possibility of using a slab saw to extract rectangular volumes from the floor slabs.

Once the rectangular material has been extracted from the structure, it would need to be scanned. The first step is to arrange it into rough groupings. It is convenient when the slabs are grouped into collections that have the same vertical height. This can be achieved when large precast slabs from buildings like the plattenblau are all cast to be the same size, or when smaller blocks of irregular concrete are stacked on top of each other to form piles that are of the same height. This process is completed using best-fit algorithms, which automatically position objects into the best arrangement to fill a quota. One can adjust the size of the gap between the two lines until you achieve the best groupings of the material, and the algorithm loops around different options until the optimal groupings are determined (Figure 11).

Having assembled the rubble into the best fitting groups, the concrete elements will next be arranged into a working configuration. The bottom layer is begun dividing the shape into a series of pieces and then using the hungarian matching algorithm to find the shapes that will fit into those positions best. Multiple iterations are made until the algorithm arrives at a distribution that makes an optimal utilisation of the material. Subsequent layers are resolved in similar manners, but with a constraint that all elements are supported on the bottom two corners for stability, spanning across the openings below. Finally, any missing gaps are filled in using the leftover library of pieces. If spaces cannot be filled custom made infill pieces can be fabricated (Figure 12).

Two particular problems for this building are the fragility stacked concrete slabs and the poor insulating properties of concrete. One solution could be the use of a diaphragm wall section where two walls of concrete slabs provide extra structural depth and a cavity for insulation. Insulation might sit in-between the two walls, with thermally broken steel connections spanning between the concrete slabs. Such a design would offer greater stability for the wall, but also insulation for the interior.

Once the basic workflow is understood, a workflow is scripted into a parametric model. This model can be adjusted by the parameters of: Base size, Floor to Ceiling Heights at each level, Window Position (Figure 13).

With this model the entire library can be matched onto a variety of shapes, allowing for a holistic optimization. Leftover material is positioned in front of the model and the amount of extra infill material required to finish the shape 
shown at the foot of the model. These two measures allow for multi-objective optimization, where the amount of infill and amount of leftover material are both minimized. The optimization algorithm can keep adjusting the basic geometry until it finds solutions that both use a lot of material and require small amounts of infill (Figures 14-15).

The algorithm described in this section was then tested in a model format. A collection of irregular concrete elements were modelled. Each piece was scanned, indexed and input into the evolutionary algorithm within the 3D modelling software Rhino, and using the parametric scripting plug-in Grasshopper. Multiple iterations were made until the software produced an optimal utilisation of the rubble material. A few patched were infilled with a brass element that was cut to fit the gap. The resulting model provides a vision of a building that can be fabricated from irregular material, without the requirement for new material to be extracted from the natural environment (Figure 16).

Such holding patterns might find their home on riverbanks in the old industrial areas of the city. The weight of concrete makes it a good candidate for transportation by water. The holding patterns could be erected on the banks of old industrial canals, ready to provide new spaces for inhabitation within the ruins of the city past.

\section{CONCLUSIONS - SEEING THE CITY AS A HOLDING PATTERN FOR MATERIAL}

There have been persistent calls in history to think of the city as a mine at this specific moment. Both Jane Jacobs and Cedric Price recognized in the post-war housing boom that these structures would not last indefinitely. In 1962

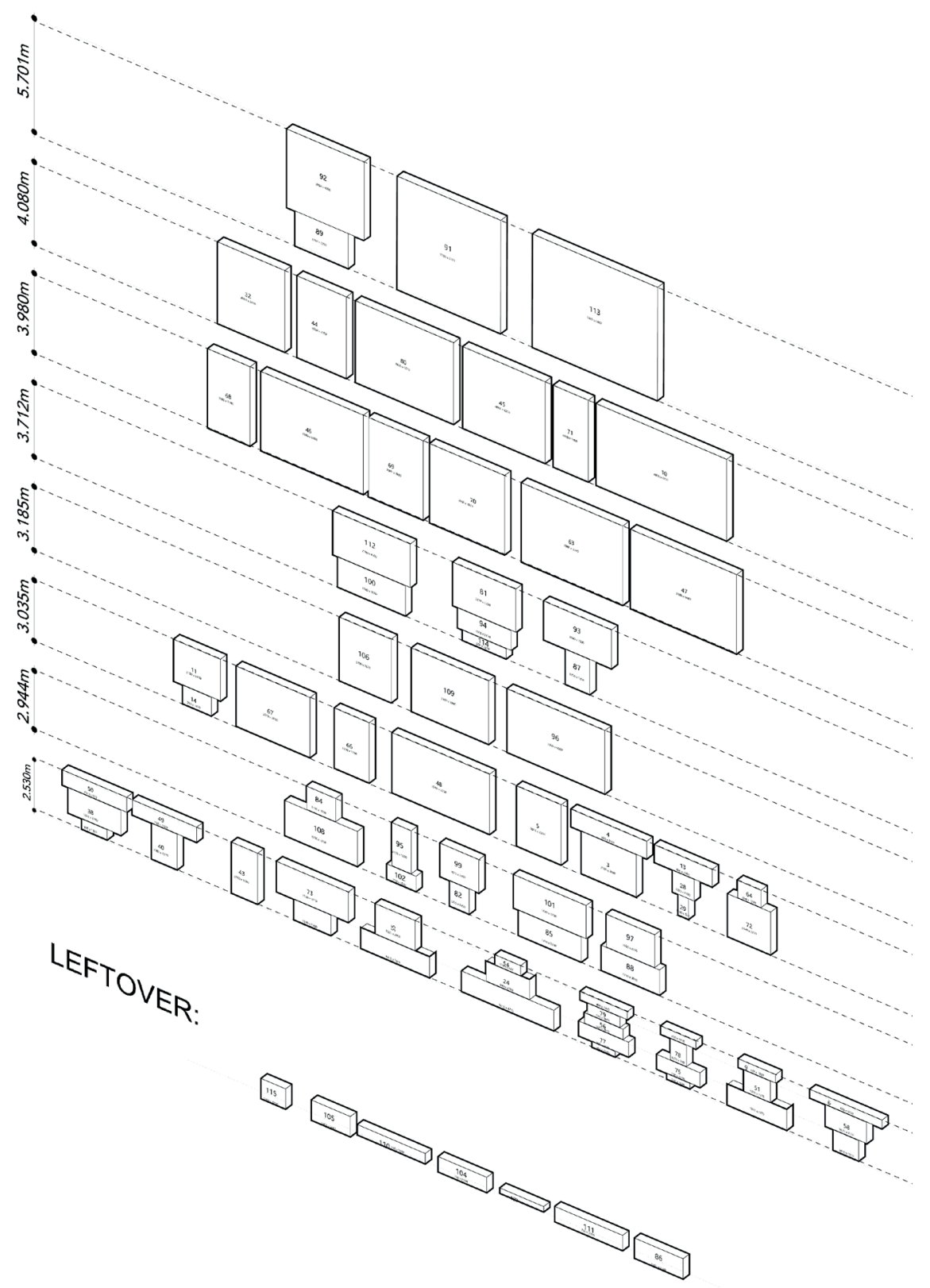

FIGURE 11: Initial organisation of rectangular floor slab elements into the best possible groupings. 


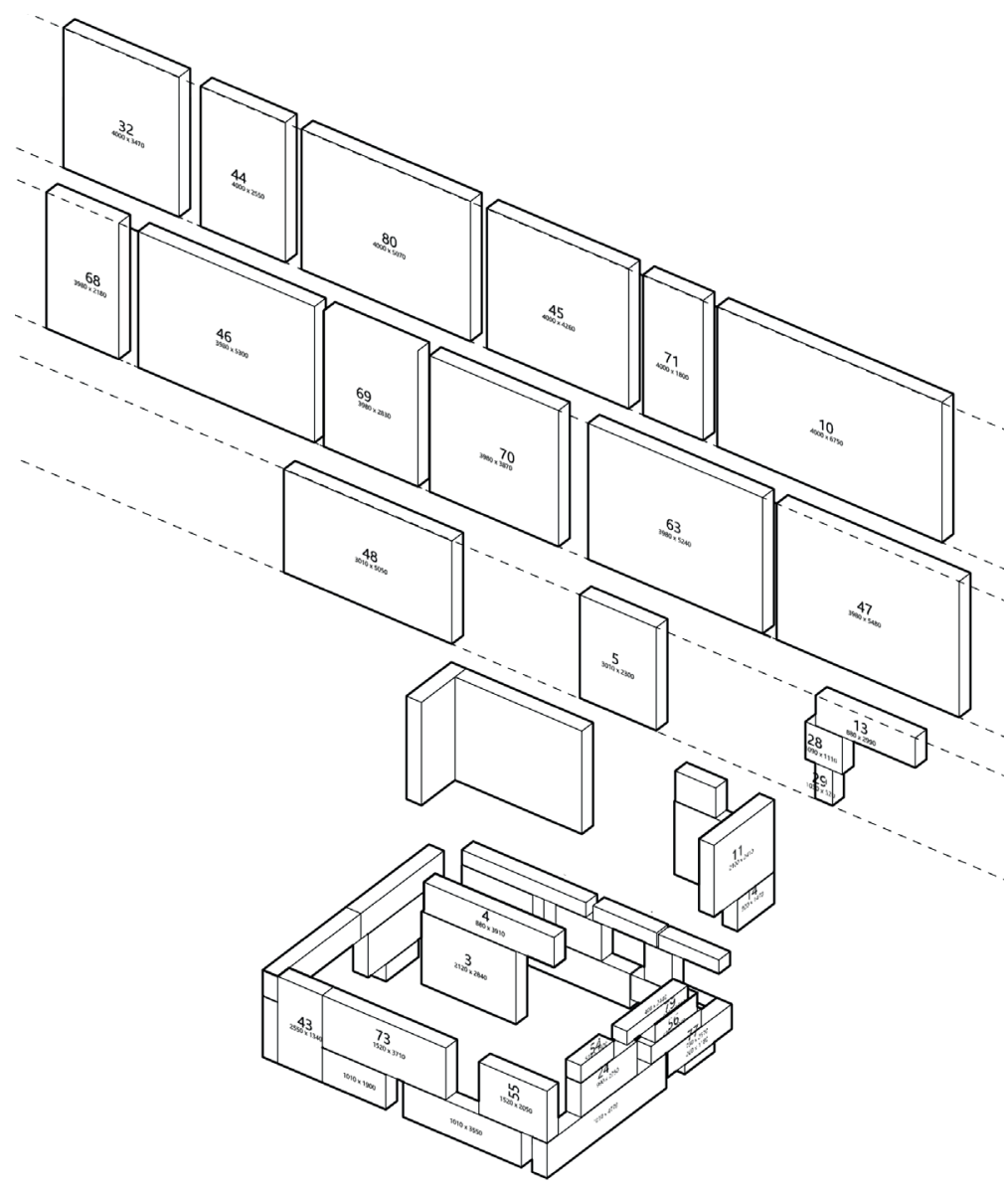

FIGURE 12: Procedural sequence for positioning irregular concrete blocks into a facade system.

Jane Jacobs suggested, "cities are the mines of the future" (Jacobs, 1961) criticizing the productions of postwar urbanism in a precursor to Rem Koolhaas' reading the city as "Junkspace" (Koolhaas, 2002). As these post-WWII buildings come to the end of their life cycles, the last decade has seen renewed interest in the problem of recycling for different ecological concerns. In 2014 Jorge Otero-Pailos who 'retrofits' buildings by barely touching the surface dust argued, "the earth simply doesn't have the energy resources to allow us to continue to demolish and rebuild everything. The logical step is to reduce our reliance on ground-up construction and instead focus on adapting the building stock we have". With a similar logic to John Soane's famous painting of the Bank of England in 1830, Reiner de Graaf in 2017 lamented the fact that no buildings can escape eventual demolition; "we build in the express knowledge that ultimately all buildings disappear", and argued that "The rubble becomes the source material for other buildings, elsewhere, for a different purpose". Researchers in at TU Delft have attempted to "prospect the urban mine of Amsterdam" with maps showing the precise volumes of different materials that exist within the built fabric of the city.

Yet this notion of the city as a resource for reconstruction is not just a niche idea in architectural histories, The debris of architecture is the frequent victim of science-fiction dystopia. Mad Max and Blade Runner speculate on the scavengers and pirates that might exist within future trashscopes of abandoned cities. Wall-e positions the robot as a way of dealing with the junk space, arranging the waste

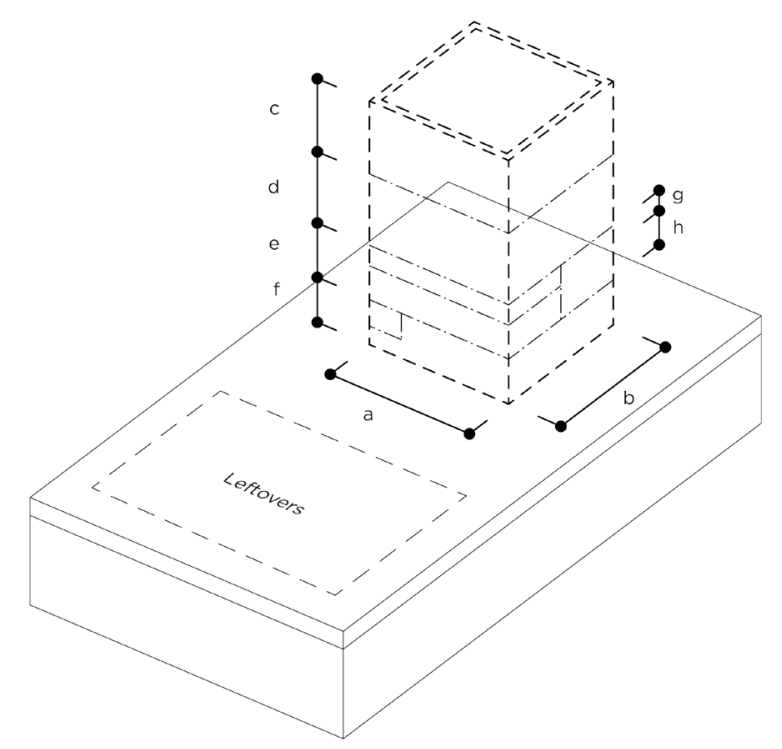

FIGURE 13: Parametric model for adjusting parameters of the proposed building. The different variables, a through to $\mathrm{h}$ can be adjusted and will yield different results from the procedural arrangement algorithm outlined above. 
of humankind into meticulous mountains. Special effects have almost anesthetised the mind to the aesthetics of how a building will come apart. There is a subtle culture that has both fetishized and devalued the destruction of the city as a daily aspect of urban life.

Yet the idea of rebuilding from the rubble of a previous city presents relationships that are more complex than the dystopian waste-scapes that we find in movies or architectural texts. It is not to remove material and replace with the "new", rather it is a city that is re-mediating itself. Which is to say that it is both a restructuring and a continuity of the past. There are perhaps two versions of this architectural phenomenon. One would be the logic of Spoila - where something has been defeated, and the new architecture is

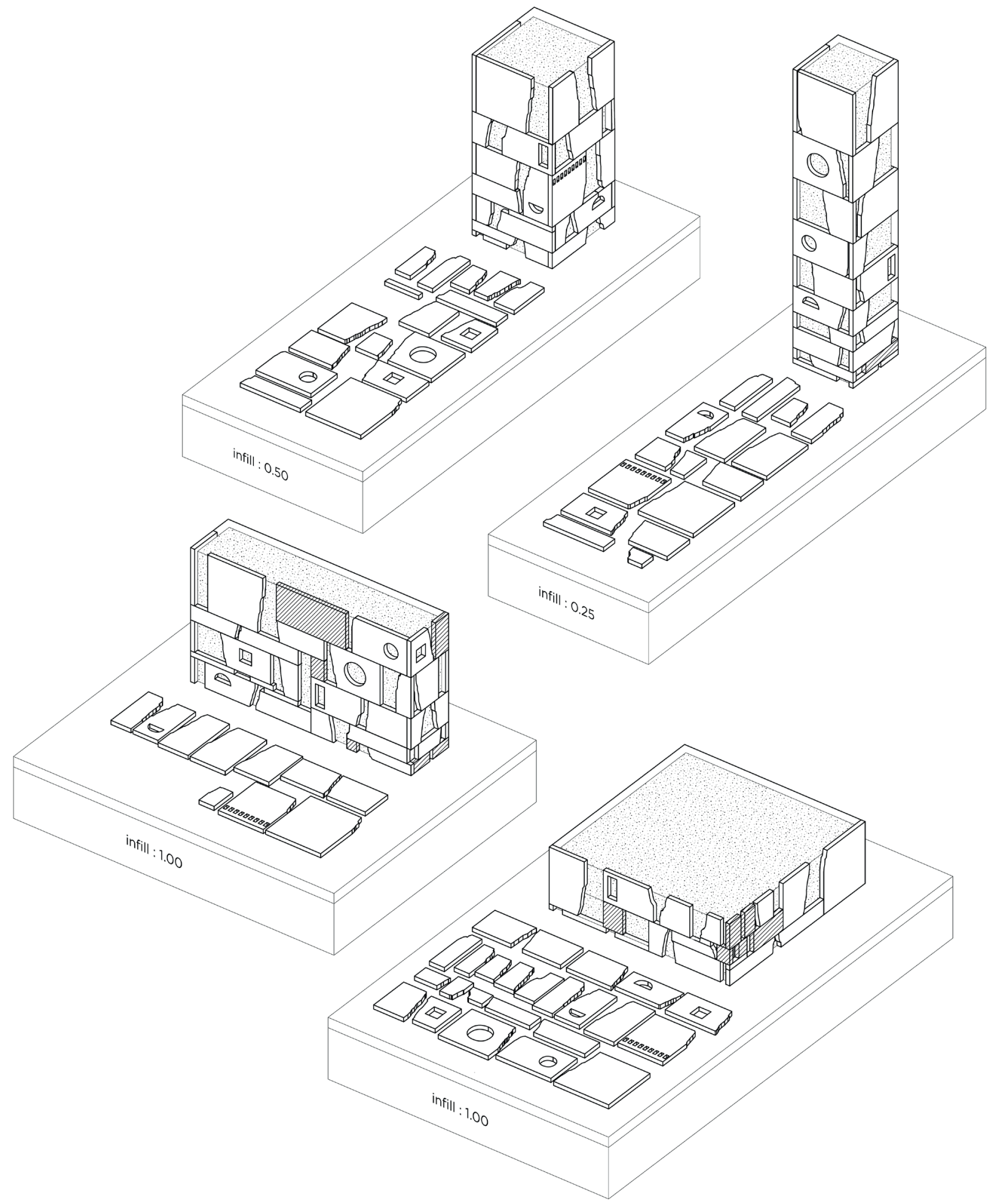

FIGURE 14: Variety of options generated by adjusting the parameters of the parametric model, and the resulting procedural concrete placement with corresponding utilization of the debris. 


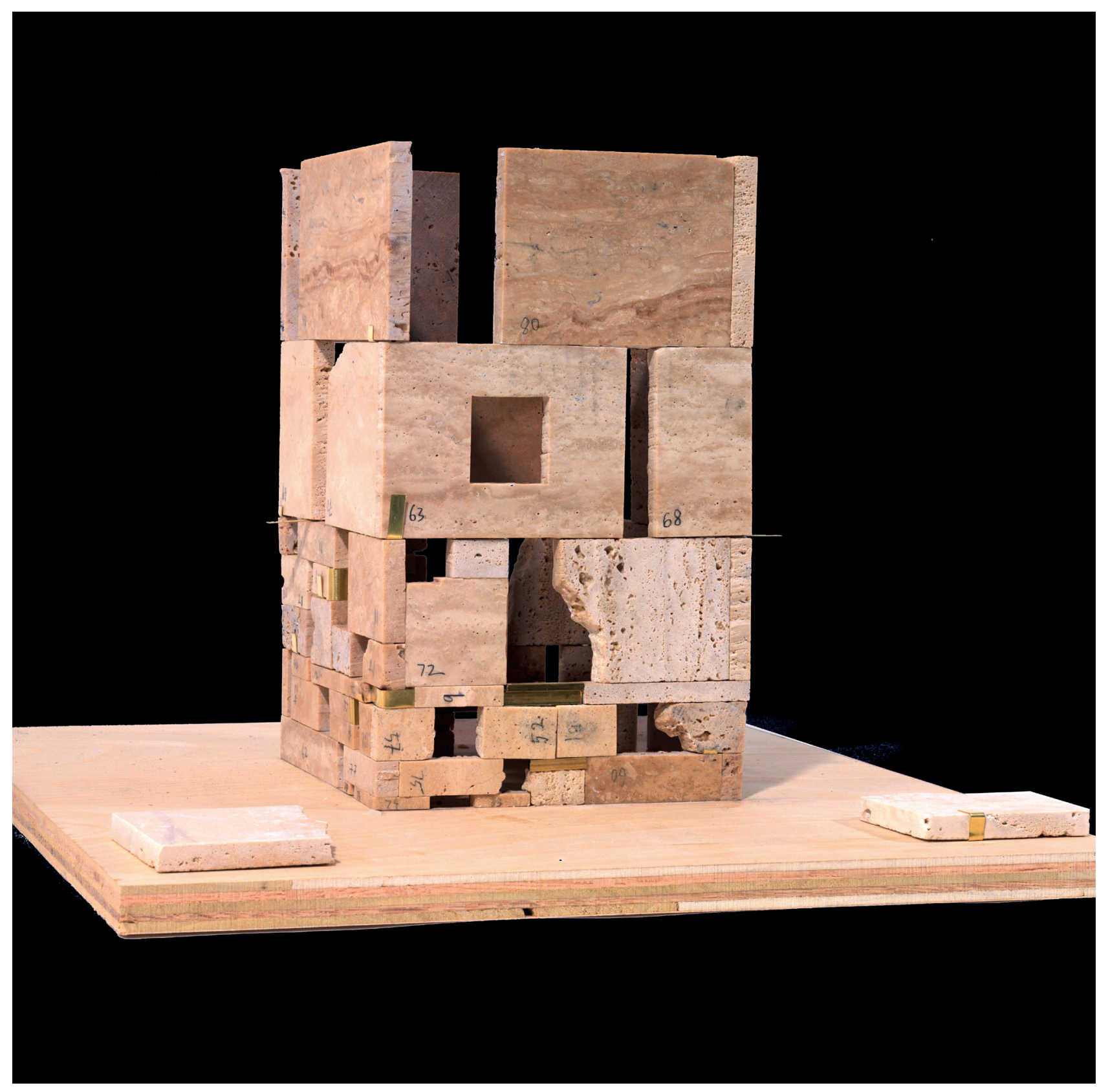

FIGURE 15: Model created by arranging a collection of irregular rectangular elements.

triumphant. The other derived from Kintsugi - the regret something was destroyed and the idea that putting it back together can yield a new sensibility. This paper is more interested in the latter.

The designs presented in this paper rely upon the indexing of material. Objects are scanned and catalogued. These catalogues are then searchable during the process of computational arrangement. The imagination is therefore that the material of the city, when a building comes to be demolished, is all indexed, allowing for designers sitting at their computer to "drop" these indexed items into new computer models for future designs. Fragments of the city therefore re-appear across time as they are used in different configurations at different moments.

Once an object is scanned, indexed and catalogued it becomes different from what it was before. If scrap material is measured and identifiable there is a new anxiety to not loose it or break it. Once its index is lost, some of its history and meaning disappear. The simple act of indexing the material of the city therefore becomes a call for preservation in its own right, and poses new possibilities for cities that might be able to last beyond the limited lifecycles that we currently build to.

\section{ACKNOWLEDGEMENTS}

This work was produced under the MIT Masters of Architecture degree program, as part of Daniel Marshall's thesis. The thesis was advised by Sheila Kennedy with readers Brandon Clifford and Caitlin Meuller. 


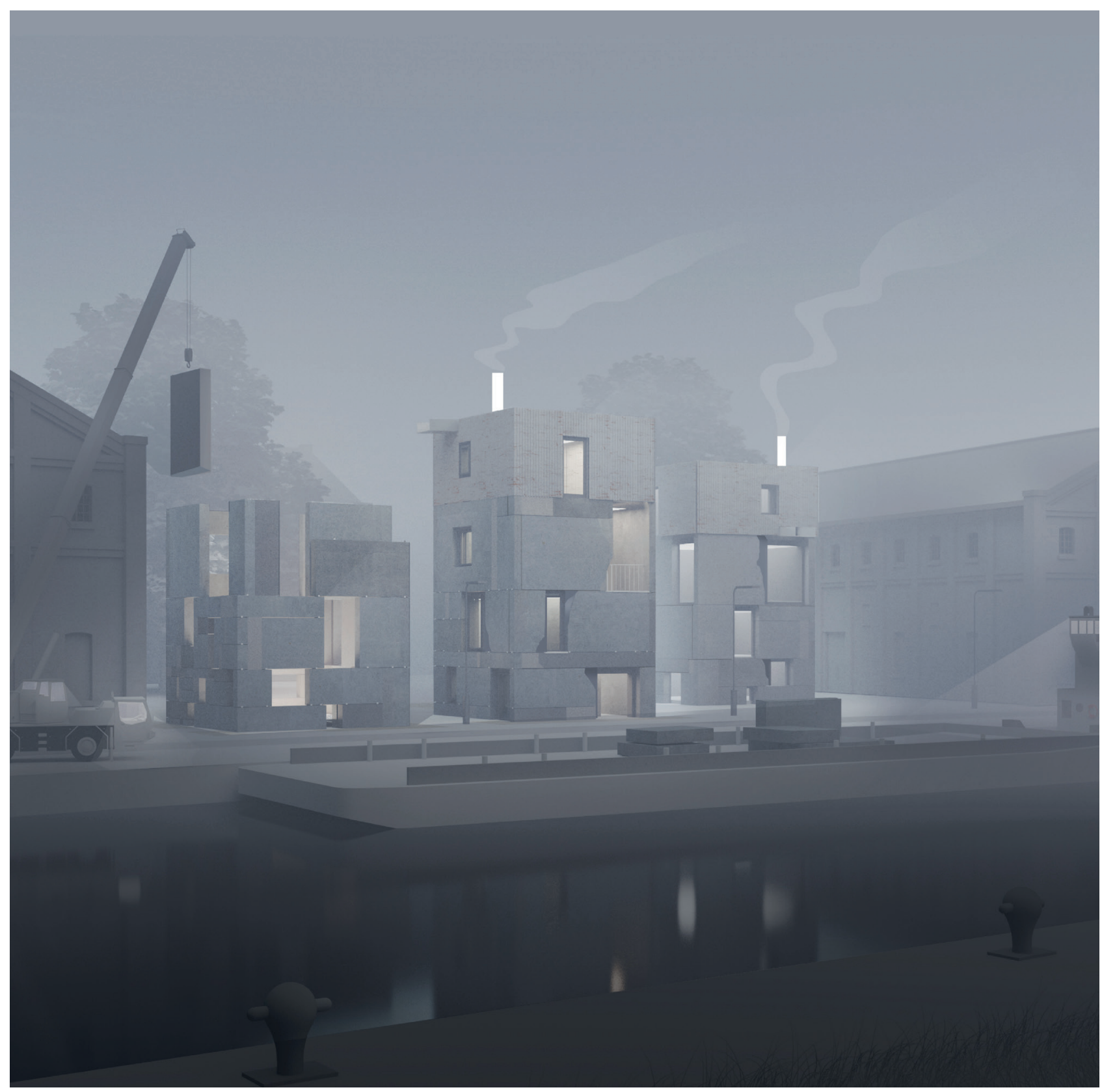

FIGURE 16: Demolition material may be placed into "holding patterns". Rather than grinding the concrete up and sending the material to landfill, perhaps architects and urbanists can find temporary uses for this material. Holding patterns would allow future generations to accumulate resource libraries for new constructions.

\section{REFERENCES}

Ahuja, R.K., Magnanti, T.L., Orlin, J.B., 1993. Network Flows: Theory, Algorithms, and Applications, Prentice Hall

Brooks, S., Smith, C.A.B., Stone, A.H., Tutte, W.T., 1940). The Dissection of Rectangles Into Squares, Duke Math Journal 7, 312-340, https://doi.org/10.1215/S0012-7094-40-00718-9

Clifford, B., 2017. The Cannibal's Cookbook: Mining Myths of Cyclopean Constructions, Matter Publishing

Cormen, T., Leiserson, C., Rivest, R., Stein, C., 2001. Introduction to Algorithms (second ed.), MIT Press and McGraw-Hill

Crowther, T.W., Glick, H.B., Covey, K.R., Bettigole C. [...], 2015. Mapping tree density at a global scale, Nature 525, 201-205, https://doi. org/10.1038/nature14967

de Graaf, R., 2017. Four Walls and A Roof the complex nature of a simple profession, Harvard University Press de Graaf, R., 2017. How Architecture Should Adapt to Climate Change, Time Magazine

Enns, J., 2010. The New Non-Standard, Thesis Dissertation

Environmental Protection Agency, Office of Resource Conservation and Recovery, 2018. Construction and Demolition Debris Generation in the United States

Fearnside, P., 2016. Environmental and Social Impacts of Hydroelectric Dams in Brazilian Amazonia: Implications for the Aluminum Industry, World Development

Gardner, J., 2018. Beneath the rubble, the Crystal Palace! The surprising persistence of a temporary mega event, World Archaeology 50, 185-199, https://doi.org/10.1080/00438243.2018.1489734.

Ghosn, R., El Hadi, J., 2016. Geographies of Trash, Actar

Ghosn, R., El Hadi, J., 2016. Trash Peaks, Seoul Biennale

Turan, I., 2016. From sink to stock: the potential for recycling materials from the existing built environment, MIT Thesis 
Koren J., 2017. Why builders of big L.A. projects are making concrete with gravel and sand shipped from Canada, L.A. Times

Jacobs, J., 1961. The Death and Life of Great American Cities" New York: Random House.

Koolhaas, R., 2002. Junkspace, October 100, 175-190, https://www. jstor.org/stable/779098

Lynn, G., 2008. Recycled Toy Furniture, Universität für angewandte Kunst Wien

Mckinsey\&Co, 2017. The growing importance of steel scrap in China

Moe, K., 2017. Empire, State \& Building, Actar

Mollica, Z., Self, M., 2016. Tree Fork Truss - Geometric Strategies for Exploiting Inherent Material Form" in Advances in Architectural Geometry

Mueller, C., Ochsendorf, J., 2015. Combining structural performance and designer preferences in evolutionary design space exploration, Automation in Construction
N.Y.C. Department of Buildings, 2018. DOB Permit Issuance: a list of permits issued by department of building since 1989

Staib, G., Dörrhöfer, A., Rosenthal, M., 2008. Components and systems - Modular building: design, construction, new technologies, Detail Magazine

Thompson, A., An evolved circuit, intrinsic in silicon, entwined with physics, Springer LNCS

U.S.E.P.A., Office of Resource Conservation and Recovery (2018) Construction and Demolition Debris Generation in the United States

U.S. Energy Information Administration, 2018. International Energy Outlook

U.S.G.S., 2018. Minerals Commodity Summaries: Cement Statistical Compendium

Witt, A. et al. 2017. Mine the Scrap, at Ars Electronica Export, Berlin, Germany 